\title{
My life: bioethics, cinema and end of life care
}

\begin{abstract}
Palliative care should be understood from a broader perspective rather than the notion of palliative medicine, offering, from an interdisciplinary approach, the required care to address the multiple dimensions of experience suffered by patients and family members facing a terminal disease. This article will assess the fundamental concepts of a patient-centered care, when it involves a progressive disease without known therapeutic alternatives. The movie My life will be used as an example through the text to compare, contrast and evidence the main ideas. There is a moment through the treatment, where it seems to be "nothing else to do", palliative care provides support, with special attention to assertive communication that facilitates family and personal confrontation in a situation of physical, mental and emotional suffering. A fundamental strategy to address these feelings is a prompt intervention, by helping advance planning of decisions about care, and adapting efforts in order to optimize the quality of life of the patient and his family. It also supports the reorientation of therapeutic interventions and considers alternatives such as sedation at the end of life as an option to control refractory symptoms.
\end{abstract}

Keywords: palliative care, bioethics, motion pictures, catastrophic illness
Volume 2 Issue 5 - 2018

\author{
Boris Julián Pinto Bustamante,' Laura Bibiana \\ Piñeros, ${ }^{2}$ Estefanía Zapata, ${ }^{2}$ Helena Arango \\ Romero, ${ }^{2}$ Lina María Arenas del Vecchio, ${ }^{2}$ \\ María José Giraldo Parra, ${ }^{2}$ Daniela González \\ Díaz $^{2}$ \\ 'Professor of Bioethics, School of Medicine and Health Sciences, \\ Del Rosario University, Department of Bioethics, El Bosque \\ University, Colombia \\ ${ }^{2}$ Medical student, School of Medicine and Health Sciences, Del \\ Rosario University, Colombia
}

\begin{abstract}
Correspondence: Boris Julián Pinto Bustamante, Professor of Bioethics, School of Medicine and Health Sciences, Del Rosario University, Department of Bioethics, El Bosque University, Colombia,Tel 3105618606,Email boris.pinto@urosario.edu.co
\end{abstract}

Received: August 12, 2018 | Published: September 10, 2018

\section{Introduction}

In the Western World, during the last decades, biomedical advances have increased the life expectancy with a subsequent increase in the incidence of chronic diseases without therapeutic options. This paradox of biomedical development generates multiple challenges for the organization of health systems, social assistance services and public health policies. Within these challenges, one of the most urgent is the development of a culture for palliative care. In this chapter, we will review this topic, using the movie My life as a teaching resource.

\section{Patient in a situation of terminal disease and palliative care}

Palliative care must be understood in a broader sense, rather than in mere terms of palliative medicine. Palliative care demands an interdisciplinary approach and a comprehensive treatment of physical and psychosocial needs at the end of life. In order to accomplish this, it requires the articulation of diverse disciplines, such as: psychology, physiotherapy, nursing, medicine, social services, community volunteers and members of the pastoral service. In contrast, palliative medicine refers to the medical practice that focuses in the medical and pharmacological care of patients that suffer from a terminal condition. This is an important argument, since palliative medicine has been understood as a subspecialty of anesthesiology, with an emphasis on the control of oncological pain (algesiology), which, although fundamental, is insufficient when confronting the symptomatic and existential complexity that supposes the imminence of death, both for the patient and his relatives. ${ }^{1}$

This holistic perspective of palliative care has a diffuse historical background, beginning from the hospices and shelters for pilgrims administered by religious communities since the Middle Ages, and passing through the hospices for the care of the dying in countries such as France and Ireland. ${ }^{2}$ In 1967, Cicely Saunders, social worker and a physician, introduced some of the fundamental concepts of modern palliative care, for instance the concept of "total pain", understood as the physical, psychological, social and spiritual suffering implicit in the process of detaching that accompanies death, as well as the introduction of continuous sedation in cases of refractory symptoms at the end of life. Perhaps, the multiple professional training of Dame Cicely Saunders, in addition to her Christian convictions and to her own life experiences related to death, contributed to the foundation of this extensive and integral perspective of palliative care.

In the movie My life (1993, directed by Bruce Joel Rubin), Bob Ivanovich successful businessman, is diagnosed with refractory endstage kidney cancer that does not respond to chemotherapy, and which finally metastasize to his brain. His condition becomes a terminal illness, which is defined by the $\mathrm{SECPAL}^{3}$ as a condition that meets the following criteria:

i. Presence of an advanced, progressive, incurable disease.

ii. Lack of reasonable possibilities to respond to the specific treatment.

iii. Presence of numerous problems or intense, multiple, multifactorial and changing symptoms.

iv. Great emotional impact on patient, family and therapeutic team, closely related to the presence, explicit or not, of death.

v. Prognosis of life less than 6 months

Illness is a complex concept that involves several definitions. Authors Leon Eisenberg ${ }^{4}$ and Allan Young ${ }^{5}$ proposed a distinction between the terms that define health impairment. Eisenberg proposes the term "disease" to denote the functional or structural abnormalities of the biological systems and components of the human body, while "illness" denotes the suffering of the patient, as the contraposition of his expectations and his reality. Young, on the other hand, describes «disease» as a physical or psychological alteration of a previously "normal" organism that implies greater vulnerability for the organism in facing environmental threats; "Illness" refers to the subjective perception of being sick, while the term "sickness" expresses the social perception of the individual's state of health and the process of self-awareness each person makes of the socially recognizable signs of the disease and illness. ${ }^{5}$ 
In this sense, the terminal illness must be redefined. ${ }^{6}$ As a medical description ("terminal disease" or terminal illness, according to the criteria of irreversibility, evolution, progression and absence of therapeutic alternatives), like the patient's non-transferable suffering and of his family («terminal illness», or terminal illness), or as the interpretation of the condition made by family and society («terminal sickness»», or terminal discomfort ${ }^{7}$ ). For this reason, it may be necessary to discuss, rather than terminally disease, of a patient with a terminal illness.

From this perspective, it should be remembered that life expectancy of less than 6 months is not an absolute criterion for the definition of terminality, because, on one hand, there are many conditions that meet all the remaining criteria and, nevertheless, do not entail death of the patient in the short term; On the other hand, the progression of the primary lesion is not a sufficient criterion to define a terminal condition either, although there is no evidence of progression of the primary tissue injury, the negative impact on quality life, family dynamics and social resources may progress. ${ }^{6}$

The vagueness of the concept "disease" is well illustrated in the story of Bob Jones. The doctor communicates to his patient the diagnosis and the prognosis of his medical condition («disease») in a precise and professional way; faced with this situation, Bob, a young man, with the expectation of being a father, with a promising professional and family future, must restructure his life project in the face of the new situation. His first reaction is one of disbelief, of rebellion before the diagnosis; he asks his doctor to restart the experimental treatment with interleukin, to which his doctor is opposed, because, according to his criterion, the tumor has grown and there is no expectation of recovery. The doctor contemplates the diagnosis from a scientific and biological perspective, although he is aware of what this mean for his patient: "he does not have much time left ... do not lose it in useless searches". But Bob, who suffers the anxiety and uncertainty of his condition, refuses to accept the medical diagnosis and begins a personal experience of spiritual search, personal redemption, legacy for his unborn child, intention to cure by means through other alternative therapies, creating by that his personal experience with the disease that threatens him ("illness").

Before the diagnosis issued by his doctor, Bob begins a grieving process from a phase of denial. He resists the forcefulness of the diagnosis and, after leaving the office, he returns furious to claim his doctor for voiding his hope: "Who the hell do you think you are? How can you take my hope like that? Let me tell you one thing: it's all I have, you understand? It's all I have left. "“

From a palliative care perspective, it is crucial during a process of revealing bad news, to leave room for hope ${ }^{8}$ which does not necessary mean offering unrealistic expectations that end up damaging the patient's confidence on the professional team. We refer to this process as understanding hope as the mental persistence of a possible positive outcome in an uncertain situation, however, knowing that this result is unlikely, ${ }^{9}$ recognizing it is part of the process of grief and should not be annulled in the doctor-patient relationship. This feeling is strongly influenced by religious convictions, personal traits, cultural background and family relationships, as well as the process in which each person and family group elaborates the meaning of a socialized condition as a terminal sickness.

As the biological course of the disease progresses, this process of adaptation is fluctuating. It is possible that they alternate periods of excessive optimism before the outcome of the situation, with periods of psychological or moral claudicating. At the same time, it is an asynchronous process because each person in the family makes a different analysis of the situation, and will be influenced by multiple factors, such as social support, beliefs, emotions, effective control of the symptoms, the representations of death and the particular valuation that each actor makes of the remaining time. ${ }^{10} \mathrm{~A}$ good communication process, based on empathy, respect for personal or religious convictions, accompanied by accurate and credible information, contribute to the consolidation of a realistic hope that impacts on the adaptation to loss.

Given the intersubjective nature of the dying process, one of the pillars of comprehensive palliative care is the timely attention to the family group of the person in terminal illness,${ }^{11}$ as their main support network for the satisfaction of their physical needs, emotional and existential. ${ }^{12}$ In this sense, the multidimensional assessment of the needs experienced by the family group is important, such as the degree of physical suffering, the adaptation to the disease, the level of information available, the supports and resources available to the family, among others. ${ }^{13}$

In the film, Bob Jones faces two contradictory news in his individual life cycle: the pregnancy of his wife and his terminal illness. These circumstances will cause Bob to reconsider his life project and, motivated by his wife, who recognizes the importance of reconciliation and forgiveness for his inner healing, reestablish fractured relationships with his family while preparing his son and his wife for his absence.

Illness and disability challenge stability and family functioning. As a web of relations based on kinship, affection, and care, the contingencies of each moment of the life cycle (normative and non-normative) mobilize the reorganization of the family network, modifying their roles, expectations, and functioning. The crisis, depending on the coping repertoires and the adaptive resources, can mean either the collapse of the family structure or its functional restructuring, in which the members experience positive changes in their relationships, increasing the cohesion as a group and improving their ability to respond to other adverse situations in the course of life. ${ }^{14}$

Illness and death can mean the resignification of life itself. After the diagnosis, Bob holds a conversation about the meaning of existence with a partner while enjoying a steam bath. Bob asks himself questions about the meaning of life, now that he faces the forcefulness of death, to which his friend, who seems healthy and young, expresses contempt for the profound existential reflection that the conversation with Bob proposes, and prefers a hedonistic and pragmatic perspective of his life experience.

In a terminal illness, palliative care can contribute to the restoration of family relationships and emotional debts. In the movie, little Bob, when he was about six years old, once asked God, through a star ("blue star, bright star, the first star I see tonight"), to have a circus in his home patio ("a real circus, with clowns and acrobats"), and invited his classmates to attend the show. The circus did not arrive and his mother censored his fantasy, after which the child is locked in the room of junk. The child, in his symbolic thinking, imagines a circus in his house, the circus that his father promised to take them, him and his brother, a promise that he did not fulfill, given his multiple occupations, and that the child, from his concrete thought, interprets 
as a failed promise. This scene suggests an affective debt of the child towards his father, from the limited time of games and affection that he shared with him. This situation of his childhood generates a rupture of family relationships. Bob moves to another city and prefers to assume a distant relationship with his family, and particularly with his father.

By the time the terminal illness is known, Bob's family is mobilized and it is necessary to recompose the interrupted links. The communication in the terminality promotes the emotional relief to the patient and his family and is a vehicle of social and emotional support for all the members of the group. A good communication process facilitates the expression of suffering, the validation of emotions, the family coping of the disease and reduces their anxiety in the face of uncertainty. ${ }^{14}$

An active listening relationship must take into account the fears of the family and the patient, their expectations about care, as well as efficiently transmitting professional recommendations and respect the anticipated wishes of the patient. The palliative care focused on the patient and his family should promote a healthy and stable family environment that allows the adequate relationship of the family with the patient, which contributes to the process of elaboration of grief. The psychological support and social support should be alert to the signs of "family claudication", as an expression of affective overload in relation to the obligations of care, ${ }^{12}$ which generates inability to respond adequately to multiple demands and needs of the patient, while putting at risk the physical and mental health of their caregivers.

In the final part of the film, this family relationship is positively transformed thanks to communication, ending in the fulfillment of the dream that once generated that break in the family relationship: enjoying a circus, a real circus, with clowns and trapeze artists, in the patio of his house.

\section{Advance directives for treatment}

An advance directive (AD) is "a written declaration, signed by a person in full possession of the mental faculties, in the presence of a witness and under the possible intervention of a notary, which specifies the conditions in which this person must be treated or not treated, if at any time he was unable to decide on his own health, due to the coming of a state of intellectual disability due to illness, accident or old age ${ }^{15} »$.

This will must be taken into account by the treating team, the legal representative, and the patient's relatives. AAD expresses the will of the person with respect to medical treatment in a possible future situation in which he does not have the necessary capacity to participate in the decision-making process. For this reason, AD can be used for the rejection of treatments that forcefully prolong the life course of the person without generating any type of recovery. The $\mathrm{AD}$ allows the patient to plan how to live their last moments, rather than stipulating a way to die. Anyone in the exercise of their capacity can prepare the document, but it is important that this decision is made based on adequate and sufficient knowledge about the risks and benefits of medical interventions, as well as the consequences when rejecting such interventions.

Some authors suggest the elaboration of the AD in two moments: a first moment in which the preferences of the person in relation to the decisions related to health are explored, starting from the system of values and individual beliefs (history of values ${ }^{16}$ or questionnaire of values ${ }^{17}$ ) on aspects such as the quality of life, religious and moral perspectives on medical care, the irreversible loss of the state of consciousness, the ability to make decisions, and a second moment, in which the personal values identified with specific decisions related to health care are articulated in a document, in a scenario in which the patient is not able to participate in the decision-making process. For this reason, it may be necessary to speak of the advance directive not only in terms of a formal document but also in advance planning of care $^{18}$ as a dynamic process. In general terms, some legislations have suggested the following requirements with respect to documents of anticipated wills:

a. It must be formalized before a notary (Spanish Law and Resolution 1051 of 2016 in Colombia).

b. It must be preceded by a mental health assessment that certifies the person's ability to express their preferences autonomously.

c. It must be formalized before witnesses (in Spain three witnesses are requested, two of whom do not live with the applicant nor have links of consanguinity).

d. The instructions must be clear and specific in their statements. The ambiguity in the terms subscribed invalidates its effective application.

e. They must not be contrary to the legal system.

f. They cannot contradict the LexArtis (the standards of excellence of the medical profession, in the circumstances of time, manner and place where it is exercised).

g. Your completion must be advised by a trusted doctor of the citizen and his family.

h. In countries such as Spain, a national file has been created for these documents, which can be consulted in databases.

i. In some jurisdictions a maximum validity is required for these documents, so the document must be revised in time to explore the persistence in the decisions subscribed by the citizen (between 3 and 5 years of validity according to some jurisdictions).

j. The document must indicate who is the substitute for the decision making that will act as a valid interlocutor with the health teams. ${ }^{18}$

In Colombia, the resolution 1051 of 2016 regulates the law 1733 of 2014 regarding the right to sign an Living Will, which is described as: "one in which every capable, healthy or ill person, in full use of his legal and mental faculties, declares in a free, conscious and informed way his willingness not to subject himself to means, treatments and/ or unnecessary medical procedures that intend to prolong his life». The porpoise of this document is to guarantee the right to the free development of personality and autonomy. ${ }^{19}$

Throughout the film, Bob Jones films different moments of his life and lessons to teach his son the knowledge about his identity as a father, his advices and skills to take on life. In these fragments of the movie he also expresses his emotions about the illness, his uncertainties and his values. Although the signing of a formal document as an living will for treatment is not evident (which is evident in "The Descendants" 2011, directed by Alexander Payne), this process of pre-recording fragments of his life constitutes an expression of values that are relevant for the decision that he made at the end of his existence. 


\section{Adjustment of therapeutic effort. The functional decline}

The primary goal of palliative care is to enhance integrally the quality of life for the patient and his family, as well as the preservation of his dignity, through the prevention and the treatment of the multiple symptoms that are developed in a terminal illness. Although the initial medical objective in the face of the disease is the search for a cure, in many cases it is not possible, then it is necessary to reorient the therapeutic effort, from cure to care, adjusting all the resources and decisions to maximize comfort and minimize suffering.

To this point, the pertinence of certain medical and invasive measures must be defined, such as the non-initiation or withdrawal of life support measures that artificially prolong life (cardiopulmonary resuscitation, mechanical ventilation, hem dialysis, administration of vasoactive drugs, chemotherapy, blood products, entreat or parental nutrition). The decision on the withdrawal or establishment of each measure should always be guided by the patient's best interest, their contribution to the overall quality of life, the vital prognosis, as well as the efficient use of resources.

As Bobs diseases progress, it is necessary to adjust the therapeutic efforts to the palliative needs of the patient and his family. At first, the doctor decided to suspend the experimental treatment with interleukin, given the costly side effects and the null clinical benefit of the treatment. At this moment, such treatment becomes a therapy that does not comply with the principle of proportionality by not offering objective benefits for the patient, as it does not modify their survival, does not improve their quality of life and does not stop the path physiological deterioration.

Subsequently, the patient's clinical situation worsens and a nurse is sent to his home for palliative support with a hospital bed. At this point, a lack of palliative care that still persists in many of the world's health systems is evident: although home care is necessary to support the patient and his family in the complexity of care at the end of life, this work cannot be transferred to a single nurse. It is necessary to coordinate the efforts of medicine, psychology, psychiatry, nursing, algesiology and in some cases pastoral care to deal not only with functional deterioration and physical pain, as Cicely Saunders called it, «total pain» that produces the feeling of multiple threat posed by the imminence of death.

The patient in terminal illness can suffer from anxiety $(30 \%)$, depression (38\%), delirium (20-45\%) and other mental symptoms. In this context, psychiatry and psychology can play a synergistic role along with palliative care in relieving psychological symptoms to offer high-quality palliative care. It should be noted that in the last $20 y e a r s$ the role of psychiatry in palliative care has thrived in some high-income countries. ${ }^{20}$

The Swiss Academy of Medical Sciences, for example, does not specify which patients will benefit from a psychiatric approach in palliative care, given the lack of consensus on the term "psychiatric futility", a term reserved in principle for cases of severe persistent anorexia and dementias, without sufficient studies in other comorbidities. Even though, it suggests its support in the case of patients with pre-existing chronic disease, where is sought an optimal treatment of the symptoms with a decrease in the ideas of self-injury and a substantial improvement in the adherence to treatment and the quality of life of the individual. Psychiatric care requires continuous communication, assessment of diagnosis and psychiatric prognosis, as well as advanced care planning, with the subsequent development of two recovery models: a clinical one; based on the remission of symptoms and functional deficits, and a personal one, focused on promoting the process of personal development, recovery of control and meaning in life despite the coexistence of the disease. ${ }^{20}$

\section{Terminal functional decline syndrome}

In the final stretch of his illness, Bob experiences a sustained decline in his physical and mental abilities. Presents weakness, pain and loss of functionality, until reaching a state of persistent bed rest, without the ability to carry out any basic self-care activity. His father shaves him; his wife moistens his lips with an ice cube and administers the medications for his symptoms; is unable, in the end, to articulate the words and presents respiratory distress. Bob has entered into a "Terminal Functional Declination Syndrome", a term that indicates the clinical state characterized by a progressive deterioration of physical functions, ${ }^{21}$ such as weight loss, frailty and mental disorders, in the context of a terminal illness. ${ }^{22}$

The evaluation of functionality of the patient is an important prognostic indicator to adjust the decisions and the appropriate treatments at each moment of the evolution. For this purpose, instruments have been developed that allow the physician the ability to identify the functional status and proceed in the most appropriate manner. For example, defining whether a patient will benefit from certain interventions such as dialysis, artificial nutrition, transfusion of blood products, etc. Some of the scales designed to assess the functional deterioration of a patient are:

\section{Status scale}

Functional assessment: the most used are the ABIVD (Basic and Instrumental Activities of Daily Life), within which are:

i. Karnofsky index: this scale qualifies the functional status between 100 (life with normal functionality) and 0 (death). A score of less than 40 is an indicator of early mortality (22).

ii. The ECOG (Eastern Cooperative Oncology Group) scale: evaluates the functional repercussion of progression in oncological conditions, with a score between 0 and 5 ( 5 equals death).

iii. Index of Independence in Activities of Daily Living (KATZ): each item is scored 0 if the patient performs the activity independently and 1 if it is dependent; based on this, it is classified into groups: from $\mathrm{A}$ to $\mathrm{G}$, where $\mathrm{A}$ corresponds to the absence of disability and $\mathrm{G}$ to severe disability. ${ }^{23}$

iv. Barthel Index: assesses autonomy for activities of daily living. A low score indicates little autonomy, poor quality of life and greater dependence. ${ }^{23}$

v. Lawton and Brody index: allows to detect the first signs of patient deterioration. Score of 0 indicates maximum dependence, and 8 total independences. ${ }^{23}$

Mental assessment: this assessment includes cognitive functions and emotional state. To evaluate cognitive functions, the Folstein Cognitive Exam (or Mini-mental State Examination) is very useful. This instrument explores temporal and spatial orientation, immediate memory and fixation, attention and calculation, language and reading. 
On the other hand, for the affective evaluation there is the Plutchik Scale that evaluates suicidal risk in depressed patients and the geriatric depression scale, ${ }^{22}$ among other instruments.

Other scales are used in palliative care, both for oncological and non-oncological conditions: Palliative Prognosis Index (PPI), Palliative Performance Status (PPS), Pap Score, Edmonton Functional Assessment Tool (EFAT), Charlson comorbidity index and some specific for certain conditions (e.g. BODE index for patients with COPD, PACSLAC and DOLOPLUS-2, for pain assessment in patients with dementia), among others. The assessment of functional status will also be important to adjust complex decisions, such as the introduction of a palliative sedation protocol.

\section{Palliative sedation}

Some medications reduce central nervous system's excitation and therefore the sensation of pain, through its hypnotic, tranquilizing and analgesic action. In some specific cases, the decrease of consciousness will be the only effective strategy to achieve satisfactory control of complex symptoms at the end of life.

In palliative sedation, ${ }^{24}$ a procedure that requires informed consent, trained health personnel administer medication to patients in terminal situation to reduce level of consciousness. This procedure is made to control suffering coming from refractory symptoms that precede death and cannot be effectively controlled with the best available resources without compromising the level of consciousness. ${ }^{25}$

The main indications for sedation are: pain, dyspnea, delirium, depression, insomnia, anguish and agitation, when the previous corresponding palliative treatments had failed (opioids for pain and dyspnea, antisecretory for bronquial secretion, antipsychotics for delirium and so on). Patients in terminal disease situation, generally suffer from more than one refractory symptoms concomitantly. Sedation can be superficial (with fluctuating consciousness periods to favor the communication with the patient) or profound; it can also be continuous or intermittent, ${ }^{25}$ always securing the minimum needed sedation in case of an incurable advanced disease. Palliative terminal sedation refers to the last hours or days of life of the individual; in this case, sedation can be profound and continuous with the purpose of relieving the suffering and agony.

Sedation levels must be monitored through specific scales (like Ramsey's) $)^{24}$ and must be proportional to the set of symptoms that are to be controlled. It must be included in the clinical story and can be adjusted depending on the patient specific situation. Pharmacological measures like blouses and other medicines to keep the proposed sedation levels must be also adapted to the patient situation.

The process of palliative sedation in agony has three main requirements:

i. Therapeutic Indication: Identification of intense suffering given by the presence of refractory symptoms. Clear record on the clinic history of prompt and imminent death given by clinical evaluations and functionality scales.

ii. Informed consent of the patient or family if the former is not competent.

iii. Medication administration until getting the wanted sedation level.
Therapeutic indication: To prescribe palliative sedation, the terminal state must be diagnosed with limited prognosis. This must be evaluated by the presence of prognosis factors, survival estimations and functional condition of the patient. Refractory symptoms that cause suffering must be stated (physical or physiological). At this point is important to assure that there are no further options to control the symptoms.

It's important to remark that the definition of refractory symptoms includes physical and not physical (psychological and existentialist) symptoms that show a clear deterioration of the individual in irreversible disease condition. Signals of this can be lost of personal sense, fear of death and expression of despair and abandonment,for which spiritual and psychological assistance can help to relieve the symptoms.

Patient Consent: An experienced team must evaluate the patient competence in to give consent. If the patient is competent, her o she must be informed about the procedure and his wishes must be fulfilled. The consent can be either oral or written and must be included in the clinic history. When the patient is not competent, preconceived wills must be investigated. When there is no written will, the medical team must evaluate with the patient relatives, wishes and values expressed by the patient before its agony phase in order to take the correct decision.

Medications: There is little scientific evidence about the medications and doses to use. Nonetheless the pharmacological groups commonly used are: benzodiazepines (first option in absence of delirium, being Midazolam the first choice medication), neuroleptics (Chlorpromazine or Levomepromazine), barbiturates (Fenobarbital) antipsychotic (Haloperidol) and anesthetics (Propofol) ${ }^{26}$ Opioids are medicated if the patient took them or if the pain or dyspnea are some of the refractory symptoms. Initial doses depend on the patient age, organic dysfunction history, drug and alcohol abuse, opioid usage and its tolerance, previous consciousness level and wishes regarding sedation. Maximum doses also depend on the patient situation but there is no justification to increase them if the symptomatic control is achieved (Table 1).

\section{Palliative sedation Vs euthanasia}

Palliative sedation is up for debate sin the nineties given de moral uncertainty that faces in the professional and family fields. ${ }^{24}$ Euthanasia and palliative sedation are frequently confused, nonetheless this perception is mistaken given the ends of both procedures are different. Palliative sedation seeks to decrease consciousness level with minimum doses of medication to achieve effective control of refractory physical or not physical symptoms. Meanwhile, euthanasia seeks to end the patient suffering through the administration of lethal doses of medications in order to produce death.

\section{Non oncological terminal disease}

The movie My life exemplifies a case of oncological terminal disease. Even so, as mentioned before, palliative cares extend to nononcological terminal diseases. One of the conditions, for example, is Multiple Sclerosis (MS), considered a chronic disease, inflammatory, autoimmune and demyelinating more common of the central nervous system. People severely affected by MS suffer from a variety of symptoms.

People severely affected by MS suffer fatigue, immobility, 
physical dysfunction, severe pain and / or psychological disorders, which include depressive symptoms that are the most frequent one. In addition, these patients suffer from severe limitations in the motor, mental and sensitive systems that can be intervened on time in order to improve them. ${ }^{27}$

Table I Little scientific evidence about the medications and doses to use

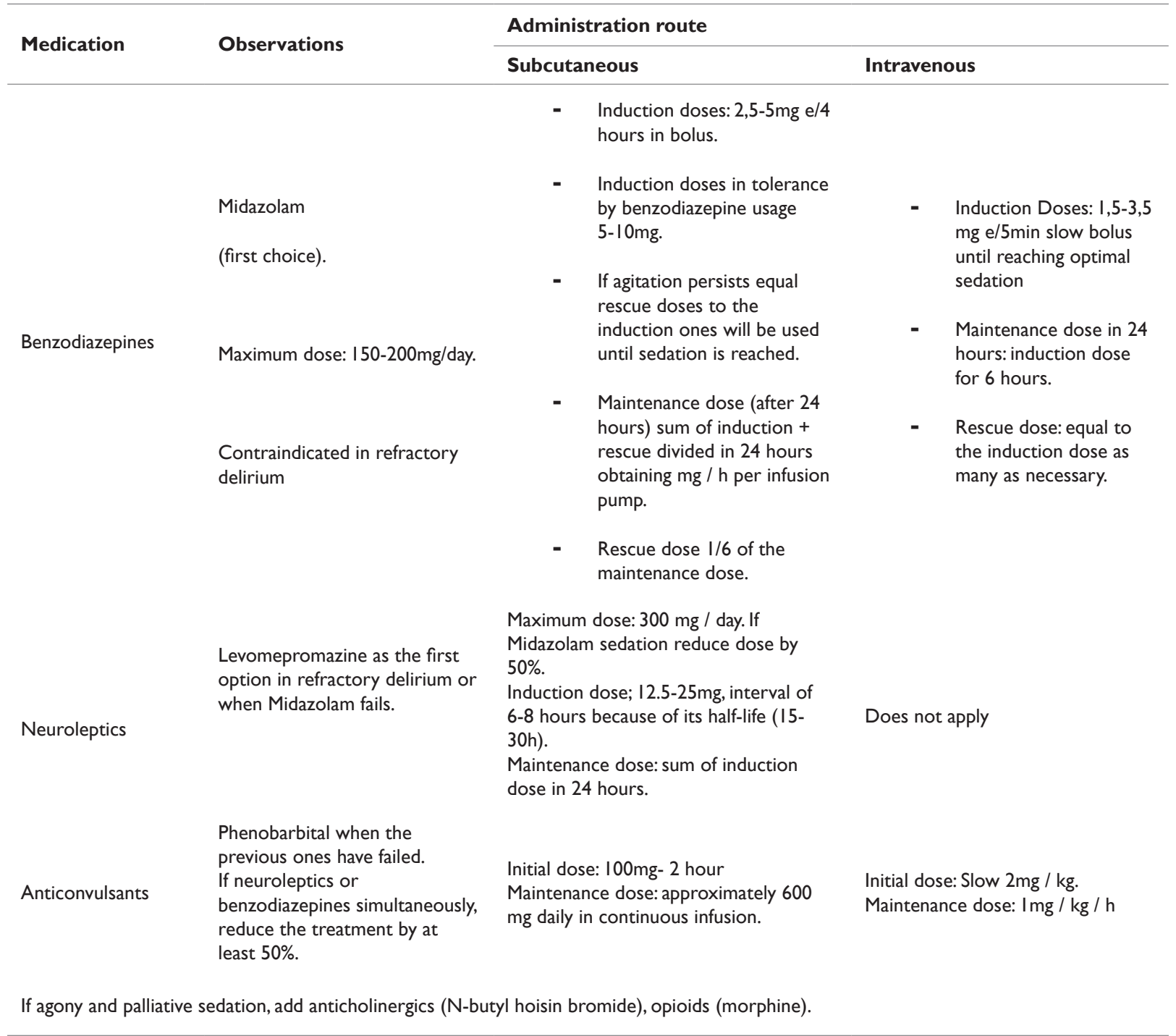

It is important to note that the prevalence of pain in MS patients is between $26 \%$ to $86 \%$, and majority of studies had ignored it as an important symptom in patients with MS. ${ }^{28}$ According to a 2012 meta-analysis, $63 \%$ of patients with this condition experience pain in different degrees of severity, ${ }^{29}$ including headache, neuropathic pain in the extremities, back pain, painful tonic spasms, trigeminal neuralgia, and so on. Headache and neuropathic pain are the most prevalent, and the tonic spasms, headaches, back pain and neuropathic pain are the most intense. ${ }^{28}$ In addition, these patients are affected by psychosocial circumstances like social isolation and loss of independence. ${ }^{27}$

One of the major limitations is that palliative care is not routinely offered to patients with non-oncological terminal diseases, like MS, motor neuron diseases, dementia and AIDS. One of the responsible entities from this happening is that health professionals usually consider palliative care as an option only to patients in terminal and agony situation, instead of recognizing palliative care as a necessary complement that must be offered simultaneously with the therapeutic purposes. ${ }^{30}$

As stated by Foley and colleagues, ${ }^{29}$ some of the priorities for physicians and professionals that treat MS patients should be ask about pain and about the characteristics of patients at risk of MS, since a better understanding of the epidemiology of pain in MS can contribute to investigation of its etiology, treatment and prevention.

\section{Conclusions}

In the reviewed movie, while the nurse does stays in final part of Bob's disease, he and his wife remain alone in the situation, devastated, without any physiological support and with no effective control of his refractory diseases. The final part of the movie doesn't show any formal protocol in the sedation of agony.Unfortunately, this is the reality in many health systems in the world, so a challenge in 
the claim of dignity at the end of life is the strengthening of palliative care, particularly in our low and middle income countries.

\section{Acknowledgements}

None.

\section{Conflict of interest}

The author declares no conflict of interest.

\section{References}

1. Pascual A. Cuidados paliativos. Humanidades Médicas. 2003;1(1):7178

2. Del Río MI, Palma A. Cuidados paliativos: historia y desarrollo. Boletín Escuela De Medicina UC, Pontificia Universidad Católica De Chile. 2007;32(1):16-22.

3. Paliativos SEdC. SECPAL: Cuidados paliativos-definición de enfermedad terminal; 2014

4. Eisenberg L. Disease and illness Distinctions between professional and popular ideas of sickness. Cult Med Psychiatry. 1977;1(1):9-23.

5. Young A. The Anthropologies of Illness and sickness. Ann Rev Anthropol. 1982;11:257-285.

6. Gonorazky SE. The unresolved issue of the "Terminal Disease" concept In: Śmigórski K, editor. Health Management-Different Approaches and Solutions. InTech; 2011. p. 415-432.

7. Osorio Carranza RM. Entender y atender la enfermedad: los saberes maternos frente a los padecimientos infantiles. Centro de Investigaciones y Estudios Superiores en Antropología Social; 2001

8. Verhaeghe STL, Van Zuuren FJ, Defloor T, et al. How does information influence hope in family members of traumatic coma patients in intensive care unit? J Clin Nurs. 2007;16(8):1488-97.

9. Verhaeghe STL, Van Zuuren FJ, Defloor T, et al. The process and the meaning of hope for family members of traumatic coma patients in intensive care. Qual Health Res. 2017;17(6):730-43.

10. Sarmiento Medina MI, Vargas Cruz SL, Sierra de Jaramillo M, et al. Análisis de la toma de decisiones al final de la vida desde una perspectiva teórica contemporánea. Revista Colombiana de Bioética. 2012;7(2):8-34.

11. Paliativos SEdC. SECPAL: Cuidados Paliativos - La familia de la persona enferma; 2014

12. Muñoz F, Espinosa J, Portillo J, et al. Cuidados paliativos: Atención a la familia palliative treatment: care for the family. Aten Primaria. 2002;30(9):576-680.

13. Benítez del Rosario MA, Salinas Martín A, Martín Ortega JJ, et al. La valoración multidimensional del paciente y de la familia. Cuidados Paliativos. 2002;29(4):237-240.

14. Austudillo W, Mendinueta C. Importancia de la familia en la terminalidad. In: Paliativos SVdC, editor. Cómo ayudar a la familia en la terminalidad; 1999. p. 23-37.
15. AgullesSimó P. Revisando el llamado "Testamento Vital”. Cuadernos de Bioética. 2010;21(2):169-183.

16. Richman KA. Advance Directives. Ethics and the Metaphysics of Medicine: Reflections on Health and Beneficence; 2004. p. 141.

17. Institute of Medicine CoCatEoL. Caring at the end of life. MicolecciónMihistorialLibros en Google play approaching death: Improving Care at the End of Life. Whashington, DC: National Academy Press; 1997. p. 67.

18. Tobar Torres JA. Las directivas anticipadas, la planificación anticipada de la atención y los derechos a la dignidad y autonomía del paciente. Estado de la cuestión a nivel internacional y su posibilidad de ejercicio en el derecho colombiano. Revista Colombiana de Bioética. 2012;7(1):140162.

19. Resolución número 1051 de 2016 , por la cual se amplía la vigencia de unos subsidios familiares de vivienda de Interés Social para áreas urbanas; 2016

20. Trachsel $\mathrm{M}$, Irwin $\mathrm{SA}$, Biller-Andorno $\mathrm{N}$, et al. Palliativepsychiatryforseverepersistent mental illness as a new approachtopsychiatry? Definition, scope, benefits, and risks. BMC Psychiatry. 2016;16(1):260.

21. Gonzalez F. Declinación funcional, una definición desde el arte. Rev Asoc Colomb Gerontol Geriatr. 2005;19(1):773-775.

22. Salazar R. La muerte del paliativista. In: Bosque Ud, editor. Univesdad El Bosque; 2009. p. 1-72

23. Fajardo Ramos E, Núñez Rodríguez M, Castiblanco MA. Valoracion integral del adulto mayor a partir de escalas de medicion. Rev EduFísica. 2012;1-15.

24. Santamaría J, García E, Roselló C, et al. Guía de sedación paliativa. recomendaciones para los profesionales de la salud de las Islas Baleares. Govern de les IllesBalears, Estratègies De salut Illes Balears; 2013. p. $1-22$.

25. Moyano J, Bogotá FSFd, Guerrero C, et al. Anestesiología y sedación paliativa: pertinencia, aspectos éticos y clínicos. Rev colombanestesiol. 2006;34(3):202-204

26. Nogueira FL, Sakata RK. Palliative sedation of terminally ill patients. Rev Bras Anestesiol. 2012;62(4):586-592.

27. Strupp JRV, Galushko M, Golla H, et al. Palliative care for severely affected patients with multiple sclerosis: when and why? Results of a Delphi survey of health care professionals. J Palliat Med. 2014;17(10):1128-1136.

28. Vidović V RM, Slivar SR, Kraml O, et al. Pain syndromes in multiple sclerosis patients - patient experience at Lipik Special hospital for medical rehabilitation. Acta Clin Croat. 2014;53(4):405-410.

29. Foley PLVH, Laird BJ, Sena ES, et al. Prevalence and natural history of pain in adults with multiple sclerosis: systematic review and metaanalysis. Pain. 2013;154(5):632-42.

30. Golla HGM, Pfaff H, Voltz R. Multiple sclerosis and palliative care perceptions of severely affected multiple sclerosis patients and their health professionals: a qualitative study. BMC Palliat Care. 2014;13(1):11. 